\title{
Numerical Analysis of Sample-Size Effect on Strength of Alumina
}

$\operatorname{AUTHOR}(S)$ :

Hoshide, Toshihiko; Sugiyama, Hiroyuki

\section{CITATION:}

Hoshide, Toshihiko ...[et al]. Numerical Analysis of Sample-Size Effect on Strength of Alumina. Journal of Materials Engineering and Performance 2013, 22(1): 1-8

\section{ISSUE DATE:}

2013-01

URL:

http://hdl.handle.net/2433/168520

\section{RIGHT:}

The final publication is available at www.springerlink.com; この論文は 出版社版でありません。引用の際には出版社版をご確認ご利用くださ $\omega_{\circ}$; This is not the published version. Please cite only the published version. 


\title{
Numerical Analysis of Sample-Size Effect on Strength of Alumina
}

Toshihiko Hoshide and Hiroyuki Sugiyama

Department of Energy Conversion Science, Graduate School of Energy Science, Kyoto University, Sakyo-ku, Kyoto 606-8501, Japan

\begin{abstract}
Statistical characteristics of strength distribution in ceramic components should be clarified because of large scatter in ceramics strength. Characteristics of strength distribution, however, depend on sample-size, i.e. the number of tested specimens. In this work, a numerical procedure in the framework of fracture mechanics was developed to estimate strength distribution of ceramics by assuming the same statistical distribution of cracks in a material. Experimental results in four-point bending tests of alumina, which were reported in a previous work, were cited to verify the validity of the developed procedure. Smooth specimens of distinct sizes as well as notched specimens with different notch shapes were used in the experiment. Monte Carlo simulations using the developed procedure were carried out to investigate effects of the sample-size on strength properties of alumina specimens with various shapes. The simulated result revealed that the experimental strength for various types of specimens was almost covered within a range of upper and lower bounds of strength simulated for the alumina. The experimental mean strength correlated with the effective volume was also included in a band range between the maximum and minimum of mean strength obtained by the simulation.
\end{abstract}

Keywords - structural ceramics, mechanical testing, sample-size, strength distribution, size effect, notched component, strength estimation, Monte Carlo simulation

\section{Introduction}

In experimental studies, a number of specimens to be tested, which is so-called a sample-size, is usually limited around 10 to 20 in one testing condition. Such a sample-size affects statistical characteristics of strength obtained in experiments. In ceramic materials, especially, it is recognized that large scatters are observed in their strength properties and caused by dispersions in shapes and locations of pre-existing flaws (e.g. Ref 1). The sample-size effect, however, cannot be appropriately evaluated by experimental investigations, because it is difficult to prepare extremely many specimens of a ceramic material. This implies that some analytical procedures are required in adequately estimating the sample-size effect on strength of ceramic components. In establishing proper analytical procedures, it should be notified that the strength of a ceramic component is dominated by a pre-existing 
flaw. Therefore, such analytical procedures should be established on basis of statistical and spatial distributions of flaws, which are generated during processing of ceramics, such as powder mixing, sintering and grinding. In a previous work (Ref 2), a numerical procedure was proposed by considering statistical and spatial distributions of flaws, and grinding-induced residual stress.

In this investigation, the numerical procedure proposed in a previous work (Ref 2 ) was developed so that simulations for the same specimen geometry could be executed many times of more than a few hundreds order. Simulations by using the developed procedure were iterated one thousand times for the same type of specimen. Sample-size effect was examined by grouping from one thousand results. It was verified whether the developed procedure should be adequately applied to the present issue. In the verification, simulated results were compared with experimental results, which had been obtained in four-point bending tests using smooth specimens with distinct sizes as well as notched specimens with different notch shapes of a sintered alumina (Ref 3 ). In addition, the applicability of the effective volume proposed by Davies (Ref 4) to the well-known size effect on strength was also discussed by using simulated and experimental results.

\section{Procedure of simulations on strength}

\subsection{Outline of simulation procedure}

The procedure in the present simulation is essentially based on a previous one ( Ref 2). The previous procedure, however, is modified by taking account of the following two points. At first, notched specimens subjected to bending are considered in the simulation, as mentioned below. It should be noted that a stress state in notched specimen cannot be evaluated theoretically. In the simulation, the stress state is evaluated by using a finite element method (FEM). The previous procedure is modified so that results in FEM analyses could be input directly in the procedure. This modification is indicated in Fig. 1, which shows a flow chart to present the whole simulation procedure. Secondarily, a source code of simulation program is improved to enable to execute large number of simulations.

In the following, an outline of the other simulation procedure will be summarized, excepting the aforementioned modifications. Ceramics as sintered materials inevitably include flaws generated in their processing. Pores among grains are formed in binding ceramic powders, and sometimes impurities are included in mixing powders and additives at the first stage of powder processing. Dangerous flaws in ceramics are also generated during grinding process in addition to sintering process. Inherent and grinding-induced flaws are distributed in a specimen. In the simulation, such flaws are modeled as circular, semi-elliptic or quarter-elliptic cracks. Number of these cracks in a specimen is determined by respective densities of inherent and grinding-induced cracks. Cracks in a specimen are randomly located 
only within the region, which is subjected to tensile stress in the specimen. It is assumed that the failure of each specimen is dominated by the crack having the maximum stress intensity factor $K_{\max }$ among all cracks distributed in the specimen. The fracture stress of one specimen is determined as the applied maximum stress $\sigma_{\mathrm{a}}$, at which a calculated value of $K_{\max }$ is just equal to the fracture toughness $K_{\mathrm{C}}$ of the specimen's material. Such a calculation is repeated for the number of iterations to reach one thousand in the present simulation. The iterated calculations give one thousand distinct data of strength.

\subsection{Procedure to evaluate strength}

It has been reported (Ref 5-8) that a fracture-mechanics based criterion for long cracks cannot be directly applied to the strength evaluation of ceramic components, which are fractured originating from small cracks. In this simulation, the following approximation (Ref 6 ) is adopted in the evaluation of a valid $K$ value for a small crack with length $a$.

$$
K=\sigma_{\mathrm{a}} \sqrt{\pi\left(a+a_{\mathrm{o}}\right)} M_{K}
$$

A length parameter $a_{\mathrm{o}}$ is a crack length to be added to the original crack length $a$. In Eq. (1), $\sigma_{\mathrm{a}}$ is the applied stress, and $M_{K}$ is a magnification factor given by considering the shape and location of the crack as well as the stress distribution in a specimen. The value of $M_{K}$ is determined using published numerical results (Ref 9-11) according to the aforementioned situations of crack. The maximum $K_{\max }$ is obtained among all $K$-values calculated for cracks located in a specimen, and the applied stress $\sigma_{\mathrm{a}}$ at the fracture of the specimen is designated as the strength $\sigma_{\mathrm{f}}$. The fracture criterion, i.e. $K_{\max }=K_{\mathrm{C}}$, combined with Eq. (1) is rewritten as follows.

$$
\sigma_{\mathrm{f}}=\frac{K_{\mathrm{C}}}{\sqrt{\pi\left(a+a_{\mathrm{o}}\right)} M_{K}}
$$

By using Eq. (2), the strength value of one specimen is finally determined by the length $a$ and the magnification factor $M_{K}$ of a crack dominating a fracture of the specimen.

A grinding-induced residual stress exists usually in a ground specimen, and affects the strength properties. Such a residual stress, however, is generally known to be compressive on the ground surface. In a previous work (Ref 2), the strength of ground ceramics was simulated by considering a grinding-induce residual stress, and it was elucidated that the strength increased up to about $40 \mathrm{MPa}$ due to compressive residual stress. In general, however, it is not easy to measure a grinding-induced residual stress, and ignoring such an effect of compressive residual stress on strength results in rather a conservative estimation of strength. 
Consequently, for practical application, the effect of grinding-induced residual stress is not considered in the present simulation.

\subsection{Procedure to determine length and positions of distributed cracks}

The density of inherent cracks is defined as the number of cracks per unit volume, while the density of cracks caused by grinding is given as the number of cracks per unit surface area because of the damage restricted on the ground surface. In determining positions of individual cracks, a Cartesian $x-y-z$ coordinate is introduced within the tensile region of a specimen under bending. In this coordinate, $x$ - and $y$-axes are respectively set to be parallel and vertical to the longitudinal direction of the specimen, and $z$-axis is in the transverse direction (width direction) of a specimen (see Fig. 2). By considering no stress gradient in the width direction ( $z$-axis) of specimen under bending mode, positions of cracks existing in an arbitrary cross section are projected in $z$ direction and onto $x-y$ plane. Therefore, in the simulation, the position $(x, y)$ of a crack is prescribed on the $x-y$ plane. For example, the position of $i$-th crack in a specimen is described as $\left(x_{i}, y_{i}\right)$ on the $x-y$ plane as shown in Fig. 2. Crack positions are randomly given by using a series of quasi-uniform random numbers. Individual cracks are classified into three types, i.e. embedded, surface and corner cracks, according to their crack position in a specimen. For a notched specimen, any cracks are not positioned in the region removed by machining a notch.

The length $a$ of each crack is given independently of its position by using a different series of quasi-uniform random numbers. The size distributions for inherent flaws formed during a sintering process and for grinding-induced flaw are respectively expressed by using two distinct functions $F(a)$ of cumulative probability as follows.

$$
F(a)=1-\exp \left[-\left(\frac{a-a_{\mathrm{L}}}{a_{\mathrm{S}}}\right)^{\alpha}\right]
$$

The above equation is a type of Weibull distribution with three parameters, i.e. location parameter $a_{\mathrm{L}}$, scale parameter $a_{\mathrm{S}}$ and shape parameter $\alpha$. These parameters are determined for inherent and grinding-induced cracks respectively. It is also presumed that distributions of inherent and grinding-induced cracks are common to smooth parts in all types of specimens. However, a different distribution of grinding-induced cracks is given in the notched part in a notched specimen.

\subsection{Crack-related parameters}

Material to be examined in this work is a pressureless sintered alumina, which was produced by the Japan Fine Ceramics Center and designated as AL-1. 
Crack-related parameters used in simulations for specimens of AL-1 are summarized in the following. Size distributions and densities of inherent and grinding-induced cracks in smooth parts are determined so that the resultant statistics of simulated strength should coincide with the reference strength data obtained in a round robin test (Ref 12), because the sample-size in the round robin test was very large. The sample-size in the round robin test was 287. The round robin test was carried out by using Japanese Industrial Standard (JIS) type specimens (Ref 13) of the same alumina in different institutions. The JIS type specimen has a dimension as $3 \mathrm{~mm}$ in thickness, $4 \mathrm{~mm}$ in width and $40 \mathrm{~mm}$ in length. The conditions of machining specimens are shown elsewhere (Ref 3). On the other hand, length distributions and densities of inherent and grinding-induced cracks in ground parts are determined by trial and error to get the best fitting for two types of notched specimens. As a summary, crack-related parameters adopted in the present simulation are listed in Tables 1 and 2.

The modification by using Eq. (1) is applied in evaluation of a valid $K$ value for a small flaw. The additional length $a_{\mathrm{o}}$ in Eq. (1) is set to be $50 \mu \mathrm{m}$, and the length $a_{\mathrm{o}}$ is found to be appropriate in fitting experimental relations of strength versus flaw-size in the alumina AL-1.

\subsection{Sample-size simulations}

An effect of sample size on the mean strength will be discussed in the following. For such a discussion, 1000 trials for respective specimen-geometry are made by creating 1000 different combinations of length and position distributions of cracks using 1000 distinct series of quasi-uniform random numbers. This implies that the simulation results in 1000 data of strength for each type of the specimen. To investigate a sample-size effect on strength properties, seven groups are constructed by randomly sampling different specimens from 1000 specimens, which have their individual strength. The grouping is as follows; 100 groups of 10 specimens per one group, 50 groups of 20 specimens, 20 groups of 50 specimens, 10 groups of 100 specimens, 5 groups of 200 specimens, 4 groups of 250 specimens, and 2 groups of 500 specimens. The sample-size in each group and its corresponding mean strength are respectively plotted on abscissa and ordinate in the following figures.

\section{Experimental background data}

Results in a previous work (Ref 3) will be used in discussing the validity of the developed procedure in the next chapter. Therefore, as experimental background date, the experimental results are summarized in the following.

The material used in strength tests is an alumina of AL-1, which has density of 3.93 $\mathrm{Mg} / \mathrm{m}^{3}$, fracture toughness of $4.4 \mathrm{MPa} \cdot \mathrm{m}^{1 / 2}$, Vickers hardness of $1.65 \mathrm{GPa}$, and Young's modulus of $380 \mathrm{GPa}$. Smooth specimens of the alumina were machined into three types with distinct dimensions of thickness, width and length as follows; $3 \mathrm{~mm} \times 4 \mathrm{~mm} \times 40 \mathrm{~mm}, 4 \mathrm{~mm}$ 
$\times 4 \mathrm{~mm} \times 40 \mathrm{~mm}$ and $6 \mathrm{~mm} \times 4 \mathrm{~mm} \times 40 \mathrm{~mm}$ (see Fig. 3). Smooth specimens having a cross-section of $3 \mathrm{~mm} \times 4 \mathrm{~mm}, 4 \mathrm{~mm} \times 4 \mathrm{~mm}$ and $6 \mathrm{~mm} \times 4 \mathrm{~mm}$ will be designated S-34, S-44 and S-64, respectively. In addition, notched specimens with two types of blunt notches as shown in Fig. 3 were prepared. Notched specimens of $4 \mathrm{~mm} \times 4 \mathrm{~mm} \times 40 \mathrm{~mm}$ with a semicircular notch of $1 \mathrm{~mm}$ root-radius, and $6 \mathrm{~mm} \times 4 \mathrm{~mm} \times 40 \mathrm{~mm}$ with a semicircular notch of $3 \mathrm{~mm}$ root-radius are designated N-R1 and N-R3, respectively. Both types of notched specimens were machined so that the minimum cross section at the notch-root should be equal to that in the standard specimen, i.e. $3 \mathrm{~mm} \times 4 \mathrm{~mm}$ (see Fig. 3). Stress concentration factors were calculated by using FEM, and they were respectively 1.71 for N-R1 and 1.26 for N-R3.

Sixteen specimens for every specimen-geometry were prepared, and tested under four-point bending with an outer span length of $30 \mathrm{~mm}$ and an inner span length of $10 \mathrm{~mm}$, in an ambient atmosphere. Statistical parameters of bending strength $\sigma_{\mathrm{f}}$ are summarized in Table 1. The shape and scale parameters are also indicated in Table 1. These parameters were obtained in the strength distribution fitted by a Weibull distribution function $F\left(\sigma_{\mathrm{f}}\right)$ of two-parameter type;

$$
F\left(\sigma_{\mathrm{f}}\right)=1-\exp \left[-\left(\frac{\sigma_{\mathrm{f}}}{\sigma_{\mathrm{S}}}\right)^{m}\right]
$$

In the above equation, parameters $\sigma_{\mathrm{S}}$ and $m$ are respectively the scale and shape parameters. No remarkable change in the shape parameter $m$ is observed as seen in Table 1; the $m$ value is around 20. A similar tendency on strength dispersion is also confirmed by examining a difference in the coefficient of variation $C V$. The value of $C V$ in Table 1 is calculated as the standard deviation divided by the mean value.

\section{Simulated Results and Discussions}

\subsection{Comparison of simulated results with strength in round robin test}

At first, simulations for the specimen with JIS-recommended shape, which was adopted in the round robin test, are conducted to verify the validity of main parameters selected to specify crack distributions. Figure 4 presents a comparison between the simulated mean strength and the experimental one. In Fig. 4, the mean strength obtained in the round robin test using 287 specimens is plotted with a solid square mark. As seen in simulated results depicted with open circular marks, the mean strength $\sigma_{\mathrm{m}}$ in a respective group changes according to the sample-size of each group. As a general trend, a scatter of mean strength becomes larger by decreasing the sample-size. Dotted curves in Fig. 4 present upper and lower bounds covering a scatter of simulated mean strength. The curves are approximated by 
expressing the variation of mean strength as quadratic functions of logarithms of sample-size. It is found that the experimental result is almost included in the range between the upper and lower bounds in the scatter of simulated mean strength.

The scatter of mean strength in respective group is discussed by using the coefficient of variation $C V$. Figure 5 shows the comparison of the result in the round robin test with simulated results. In Fig. 5, too, dotted curves present upper and lower bounds covering a scatter of simulated $C V$. They are also approximated in a similar way as the case in Fig. 4 . Although the value of $C V$ in the round robin tests is a little bit smaller compared with the lower bound of simulated results, such a difference may be within a permissible range.

Consequently, it is may be concluded that the parameters of crack distributions adopted in the present simulation are adequately applied to the estimation of strength of the alumina AL-1.

\subsection{Results in strength simulated for various specimen-geometry}

Figures 6-10 present the mean strength $\sigma_{\mathrm{m}}$ obtained by simulations for S-34, S-44, S-64, $\mathrm{N}-\mathrm{R} 1$ and N-R3, respectively. In every figure, the strength range in the ordinate is the same set to be $150 \mathrm{MPa}$ so that an extent in strength scatter could be directly compared. Two dotted-curves in these figures present the upper and lower bounds, which can cover a scatter of simulated mean strength depending on the sample-size. These curves are approximated by expressing the variation of mean strength as quadratic functions of logarithms of sample-size, which pass the data point at the sample-size of 1000.

As aforementioned, the sample-size in the previous experiment is sixteen for every type of specimen, which is very small compared with the sample-size in the round robin test. The experimental results of mean strength, however, are sufficiently included within the range of simulated scatter bounds. Variations in simulated mean strength are almost similar, excepting $\mathrm{N}-\mathrm{R} 1$ type specimen, i.e. the notched specimen with a notch-root-radius of $1 \mathrm{~mm}$. The largest dispersion in the simulated mean strength is observed in N-R1 type specimen. It is speculated that such a large scatter observed in N-R1 type specimen may be attributed to the steepest stress-gradient around a notch. A dominant crack located around notch-root reduces strength, while a dominant crack existing away from notch-root increases strength. Consequently, it is suggested that a steeper stress-gradient results in a larger dispersion in strength. Although figures associated with $\mathrm{CV}$ for various types of specimens are not included in this paper, it is also confirmed that the experimental results on $C V$ are included within the range of simulated scatter bounds.

Statistical parameters of 1000 strength data obtained by simulations for various types of specimens are summarized in Table 4. As seen in the table, the mean strength $\sigma_{\mathrm{m}}$ of 1000 strength data in the smooth specimen decreases with increasing the cross-section area, i.e. the specimen volume. The table shows that the shape parameter $m$ obtained in the simulation is 
around 20 for smooth specimens and around 15 for notched specimens.

\section{Effective volume and its correlation to bending strength}

In the above, five different specimen-geometries are investigated, and the dependence of strength on the specimen-geometry is clarified. Such a specimen-geometry effect on strength has been successfully explained by using the effective volume in ceramic materials (Ref 14). In the following, the influence of specimen-geometry on strength will be discussed incorporating the sample-size effect. For a homogeneous material with a volume $V$ under an arbitrary stress state, the effective volume $V_{\mathrm{E}}$ is defined as the following volume integration $(\operatorname{Ref} 4)$.

$V_{\mathrm{E}}=\int_{V}\left(\frac{\sigma_{v}}{\sigma_{\mathrm{R}}}\right)^{m} \mathrm{~d} v$

Stress parameters $\sigma_{v}$ and $\sigma_{\mathrm{R}}$ in the integrated part of Eq. (6) are respectively a stress in an infinitesimal volume $\mathrm{d} v$ and a representative stress in specimen. The power parameter $m$ in Eq. (6) is the shape parameter in a two-parameter Weibull distribution function, which is fitted to a strength distribution. The maximum stress generated in a component is usually adopted as $\sigma_{\mathrm{R}}$ and is used as its fracture strength.

The effective volume is correlated with the bending strength in simulations and experiments. The effective volume is calculated for a smooth specimen under four-point bending with outer span of $30 \mathrm{~mm}$ and inner span of $10 \mathrm{~mm}$, which are adopted in the present simulation and its related experiments. By using a theoretical stress distribution in a smooth specimen under bending, the effective volume for the smooth specimen is calculated from Eq. (6) as follows.

$V_{\mathrm{E}}=V \frac{m+3}{6(m+1)^{2}}$

In Eq. (7), $V$ is the whole volume within the outer span of the specimen. Since it is reasonable to consider that no fracture occurs in the region under compression, the region of $\sigma_{v} \leq 0$ is excluded in the volume integration of Eq. (6). Differently from the case in a smooth specimen, however, there is no theoretical stress distribution in a notched specimen. Therefore, the effective volume for a notched specimen is evaluated by using stress distribution given in an FEM analysis and by substituting a summation for the volume integration. The effective volume for the notched specimen is approximately calculated by using the next equation. 
$V_{\mathrm{E}}=\sum_{i}\left(\frac{\sigma_{i}}{\sigma_{\max }}\right)^{m} V_{i}$

In Eq. (8), $\sigma_{i}$ and $\sigma_{\max }$ are respectively the normal stress in the $i$-th element in the FEM mesh of a notched specimen and the maximum stress calculated by the FEM analysis for the notched specimen. The volume of the $i$-th element, $V_{i}$, is given by multiplying the area of the element by its thickness. The summation with respect to $i$ in Eq. (8) is made only for elements, in which the normal stress in the longitudinal direction of a specimen is positive, for the same reason as in the volume integration. A direct verification on the validity of the evaluation using Eq. (8) cannot be made for the notched specimens due to lack of theoretical stress distribution. However, the validity is verified for smooth specimens by confirming the difference within $\pm 5 \%$ between the theoretical calculation by Eq. (7) and the result approximated by Eq. (8).

The mean values of strength for ceramic components with different effective volumes of $V_{\mathrm{E} 1}$ and $V_{\mathrm{E} 2}$ are respectively denoted by $\sigma_{\mathrm{ml}}$ and $\sigma_{\mathrm{m} 2}$. In this case, the relationship among these parameters is given by the next equation (Ref 14).

$$
\frac{\sigma_{\mathrm{m} 2}}{\sigma_{\mathrm{m} 1}}=\left(\frac{V_{\mathrm{E} 2}}{V_{\mathrm{E} 1}}\right)^{-1 / m}
$$

When the mean strength $\sigma_{\mathrm{m} \text {, ref }}$ corresponding to a reference effective volume $V_{\mathrm{E} \text {,ref }}$ is given, the relation between an arbitrary effective volume $V_{\mathrm{E}}$ and its corresponding mean strength $\sigma_{\mathrm{m}}$ is expressed from Eq. (9) as follows.

$\sigma_{\mathrm{m}}=\sigma_{\mathrm{m}, \text { ref }}\left(V_{\mathrm{E}, \mathrm{ref}}\right)^{1 / m}\left(V_{\mathrm{E}}\right)^{-1 / m}$

This implies that the relation between $\sigma_{\mathrm{m}}$ and $V_{\mathrm{E}}$ can be expressed with a straight line when values of these parameters are plotted on log-log diagram.

The effective volume $V_{\mathrm{E}}$ is evaluated by using Eq. (7) or Eq. (8) for the corresponding specimen type. Values of $m$ for five types of specimens were obtained by fitting the strength distributions with two-parameter Weibull distribution functions for respective types of specimens. As mentioned previously, however, the $m$ value for each type of specimen in simulations and experiments was different each other. Therefore, the averaged $m$ values, i.e. 18.3 for the simulation and 22.2 for the experiment, were employed in calculating $V_{\mathrm{E}}$. In this case, $m$-values for five types of specimens were averaged irrespective of specimen types for 
simulated and experimental results respectively. Figure 11 shows the relation between the mean strength $\sigma_{\mathrm{m}}$ and the effective volume $V_{\mathrm{E}}$ calculated as above, for each type of specimen. As for simulated mean strength plotted in Fig. 11, the mean strength for sample-size of 1000 is depicted with solid marks, and error-bars indicate ranges of the maximum and minimum values of mean strength for sample-size of 10. The solid straight-line in Fig. 11 represents the relation of Eq. (10) obtained by regression for the simulated mean strength for sample-size of 1000 , which is expressed as follows.

$\sigma_{\mathrm{m}}=384\left(V_{\mathrm{E}}\right)^{-1 / 18.3}$

The $m$-value is expected to be 18.3 by comparing Eq. (11) with Eq. (10), and the value coincides with the averaged one used in calculating the effective volume for the simulation. Two dotted straight-lines indicate the relations by regressions for the maximum and minimum values of mean strength for sample-size of 10. These dotted lines give respectively the upper and lower bounds in simulated strength scatter in the correlation of the mean strength with the effective volume. As seen in Fig. 11, experimental results are almost covered between the two dotted lines. This suggests that a variation in experimentally measured strength may be estimated within the range of the mean strength simulated by using the present procedure.

\section{Conclusions}

In this work, the effect of sample-size, i.e. number of tested specimens, on statistical properties of strength in alumina was investigated by using a developed simulation procedure in framework of fracture mechanics.

A procedure for numerical simulation of Monte Carlo type was developed based on a previously proposed procedure to estimate strength of ceramic materials by taking account of size and spatial distributions of cracks, and grinding-induced residual stress. A criterion of constant fracture toughness and characteristics of crack distribution in a material were assumed in the simulation procedure. The crack distribution was determined so that the strength characteristics in a round robin test using many specimens of reference type could be fitted appropriately. Simulations using the developed procedure were carried out 1000 times for three types of smooth specimens and two types of notched specimens of a sintered alumina. Effects of sample-size on strength properties were clarified. It was found that a scatter in simulated mean strength increased with decreasing sample-size. To verify the validity of the developed procedure, simulated mean strength was compared with experimental one for five respective types of specimens. The result showed that the experimental mean strength obtained using a small sample-size was almost covered within a range of upper and lower bounds of mean strength simulated for various sample-size. The 
relations between the mean strength in experiments and the effective volume for five distinct types of specimens were included within a band range of the simulated mean strength correlated with the effective volume. Finally, it may be concluded that the presently developed procedure is useful in estimating the variation in mean strength, which is ordinarily obtained using ceramic specimens of a small sample-sizes in experiment.

\section{References}

1. T. Hoshide, Strength Characteristics of Structural Ceramics, Mater. Sci. Res. Int., 2, 1996, p 220-228.

2. T. Hoshide and J. Fujita, Simulation of Strength Distribution in Ground Ceramics by Incorporating Residual Stress Effect, J. Mater. Eng. Perform., 17, 2008, p 627-632

3. T. Hoshide, J. Murano and R. Kusaba, Effect of Specimen Geometry on Strength in Engineering Ceramics, Eng. Fract. Mech., 59, 1998, p 655-665

4. D.G.S. Davies, The Statistical Approach to Engineering Design in Ceramics, Proc. British Ceram. Soc., 22, 1973, p 429-452

5. T. Hoshide and M. Masuda, Dependence of Strength on Size of Flaw Dominating Fracture in Ceramics, Mater. Sci. Res. Int., 1, 1995, p 108-113

6. T. Hoshide and T. Inoue, Simulation of Anomalous Behavior of a Small Flaw in Strength of Engineering Ceramics, Eng. Fract. Mech., 38, 1991, p 307-312

7. T. Hoshide, H. Furuya, Y. Nagase and T. Yamada, Fracture Mechanics Approach to Evaluation of Strength in Sintered Silicon Nitride, Int. J. Fract., 26, 1984, p 229-239,

8. T. Hoshide, Grain Fracture Model and Its Application to Strength Evaluation in Engineering Ceramics, Eng. Fract. Mech., 44, 1993, p 403-408

9. Stress Intensity Factors Handbook, Vols. 1 \& 2, Y. Murakami, A. Aoki, N. Hasebe, Y. Itoh, H. Miyata, N. Miyazaki, H. Terada, K. Tohgo, M. Toya and R. Yuuki, Ed., Pergamon Press, 1987.

10. Stress Intensity Factors Handbook, Vol. 3, Y. Murakami, M. T. Hanson, N. Hasebe, Y. Itoh, K. Kishimoto, H. Miyata, N. Miyazaki, H. Terada, K. Tohgo and R. Yuuki, Ed., The Society of Materials Science, Japan, and Pergamon Press, 1992.

11. Stress Intensity Factors Handbook, Vols. 4 \& 5, Y. Murakami, N. Hasebe, Y. Itoh, K. Kishimoto, H. Miyata, N. Miyazaki, N. Noda, C. Sakae, H. Shindo and K. Tohgo, Ed., The Society of Materials Science, Japan, and Elsevier Science Ltd., 2001.

12. Working-Group on Reference Ceramic Materials Sub-Committee on Ceramic Strength, Committee on Fatigue, Round Robin Tests on flexure Strength of Reference Ceramic Materials, J. Soc. Mater. Sci. Japan, 44, 1995, p 249-255

13. "Testing Method for Flexural Strength (Modulus of Rupture) of High Performance Ceramics," JIS R 1601, Japanese Industrial Standard, Japanese Standards Association, 1995

14. R.W. Davidge, Mechanical Behaviour of Ceramics, Cambridge University Press, 
Cambridge, UK, 1979, p 138 
Table 1 Parameters for inherent crack adopted in simulations

\begin{tabular}{|c|c|c|c|c|}
\hline $\begin{array}{c}\text { Density } \\
\left(1 / \mathrm{mm}^{3}\right)\end{array}$ & $\begin{array}{c}\text { Shape } \\
\text { Parameter } \\
\alpha\end{array}$ & $\begin{array}{c}\text { Location } \\
\text { Parameter } \\
a_{\mathrm{L}}(\mu \mathrm{m})\end{array}$ & $\begin{array}{c}\text { Scale } \\
\text { Parameter } \\
a_{\mathrm{S}}(\mu \mathrm{m})\end{array}$ & $\begin{array}{c}\text { Fraction of } \\
\text { corner cracks } \\
\text { to surface } \\
\text { cracks }(\%)\end{array}$ \\
\hline 1.25 & 7.7 & 1.0 & 25 & 2.0 \\
\hline
\end{tabular}

Table 2 Parameters for grinding-induced crack adopted in simulations

\begin{tabular}{|c||c|c|c|c|c|}
\hline $\begin{array}{c}\text { Type of } \\
\text { specimen }\end{array}$ & $\begin{array}{c}\text { Density } \\
\left(1 / \mathrm{mm}^{2}\right)\end{array}$ & $\begin{array}{c}\text { Shape } \\
\text { Parameter } \\
\alpha\end{array}$ & $\begin{array}{c}\text { Location } \\
\text { Parameter } \\
a_{\mathrm{L}}(\mu \mathrm{m})\end{array}$ & $\begin{array}{c}\text { Scale } \\
\text { Parameter } \\
a_{\mathrm{S}}(\mu \mathrm{m})\end{array}$ & $\begin{array}{c}\text { Fraction of } \\
\text { corner cracks } \\
\text { to surface } \\
\text { cracks }(\%)\end{array}$ \\
\hline $\begin{array}{c}\text { Smooth } \\
\text { parts }\end{array}$ & 0.25 & 2.0 & 0.1 & 2.0 & 2.0 \\
\hline $\begin{array}{c}\text { Notched } \\
\text { parts }\end{array}$ & 5.0 & 2.0 & 5.0 & 8.0 & 2.0 \\
\hline
\end{tabular}

Table 3 Statistics of bending strength in experiments

\begin{tabular}{|c|c|c|c|c|c|}
\hline Specimen ID & S-34 & S-44 & S-46 & N-R1 & N-R3 \\
\hline \hline Mean strength $(\mathrm{MPa})$ & 375 & 359 & 395 & 453 & 430 \\
\hline Coefficient of variation $C V(\%)$ & 5.5 & 6.2 & 6.2 & 4.2 & 5.4 \\
\hline Shape Parameter $m$ & 23.3 & 21.0 & 18.5 & 26.2 & 22.1 \\
\hline Scale parameter $\sigma_{\mathrm{S}}$ & 384 & 369 & 406 & 462 & 440 \\
\hline
\end{tabular}

Table 4 Statistics of bending strength in simulations

\begin{tabular}{|c|c|c|c|c|c|}
\hline Specimen ID & S-34 & S-44 & S-46 & N-R1 & N-R3 \\
\hline \hline Mean strength $(\mathrm{MPa})$ & 373 & 371 & 369 & 469 & 425 \\
\hline Coefficient of variation $C V(\%)$ & 7.30 & 7.23 & 7.11 & 11.5 & 8.67 \\
\hline Shape Parameter $m$ & 19.9 & 20.3 & 20.9 & 15.3 & 15.0 \\
\hline Scale parameter $\sigma_{\mathrm{S}}$ & 383 & 380 & 378 & 484 & 440 \\
\hline
\end{tabular}




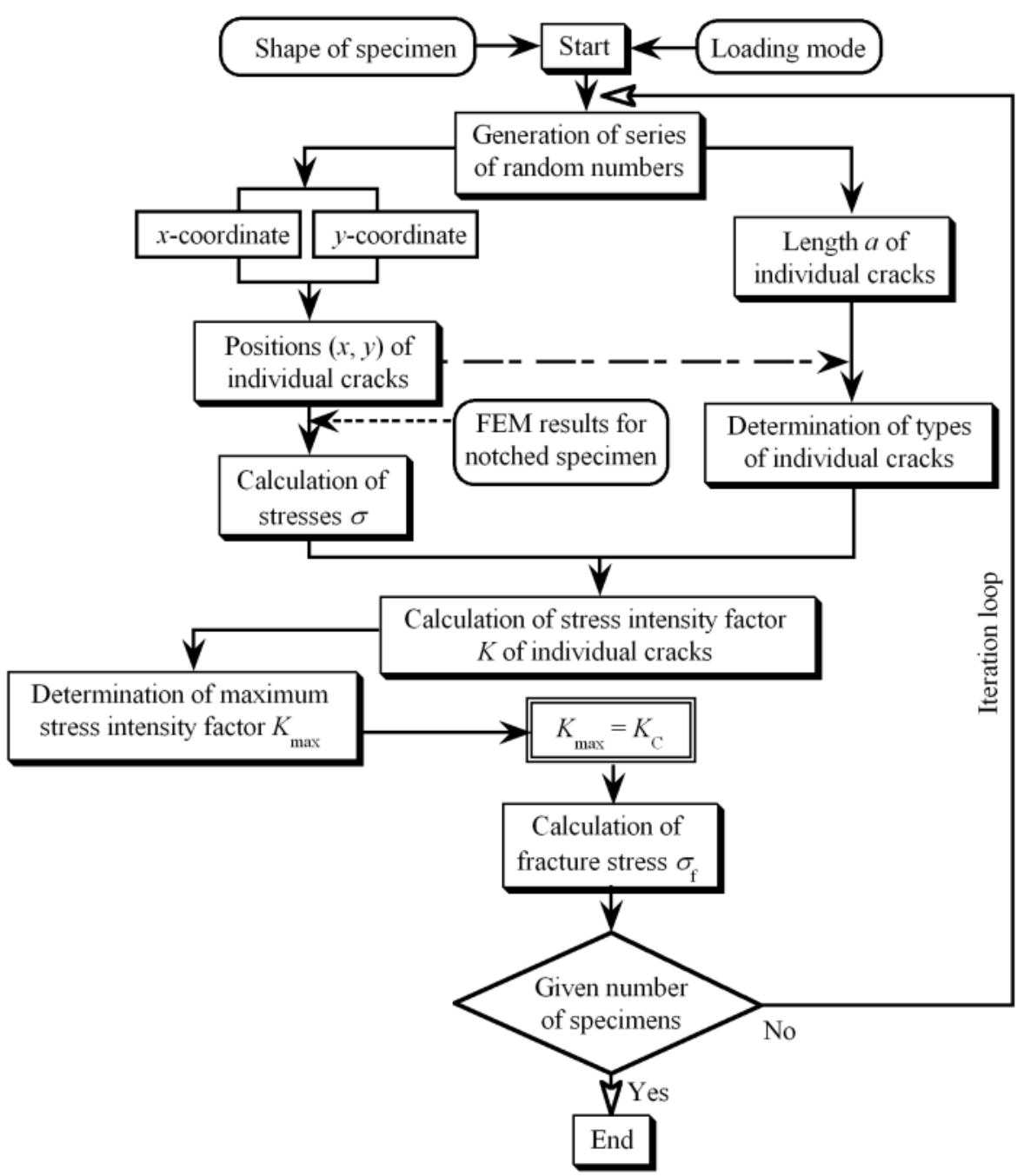

Fig. 1. Flow chart of simulation.

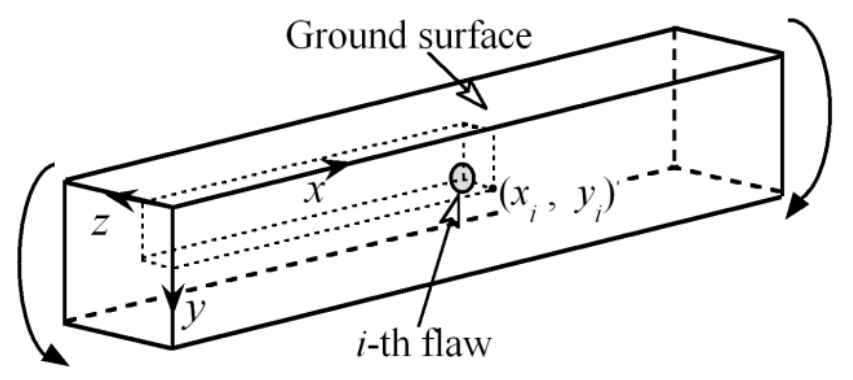

Fig. 2. Cartesian coordinate in specimen subjected to bending. 

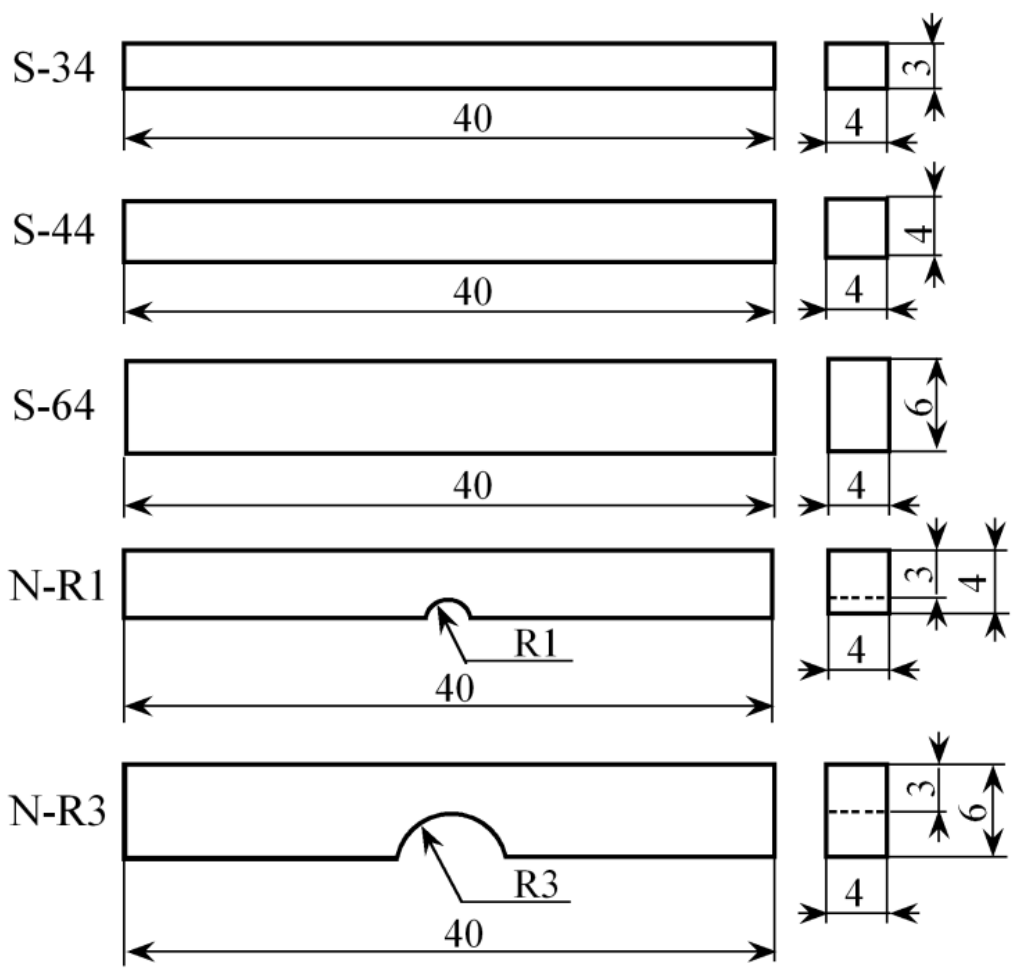

Fig. 3. Specimen geometries to be examined.

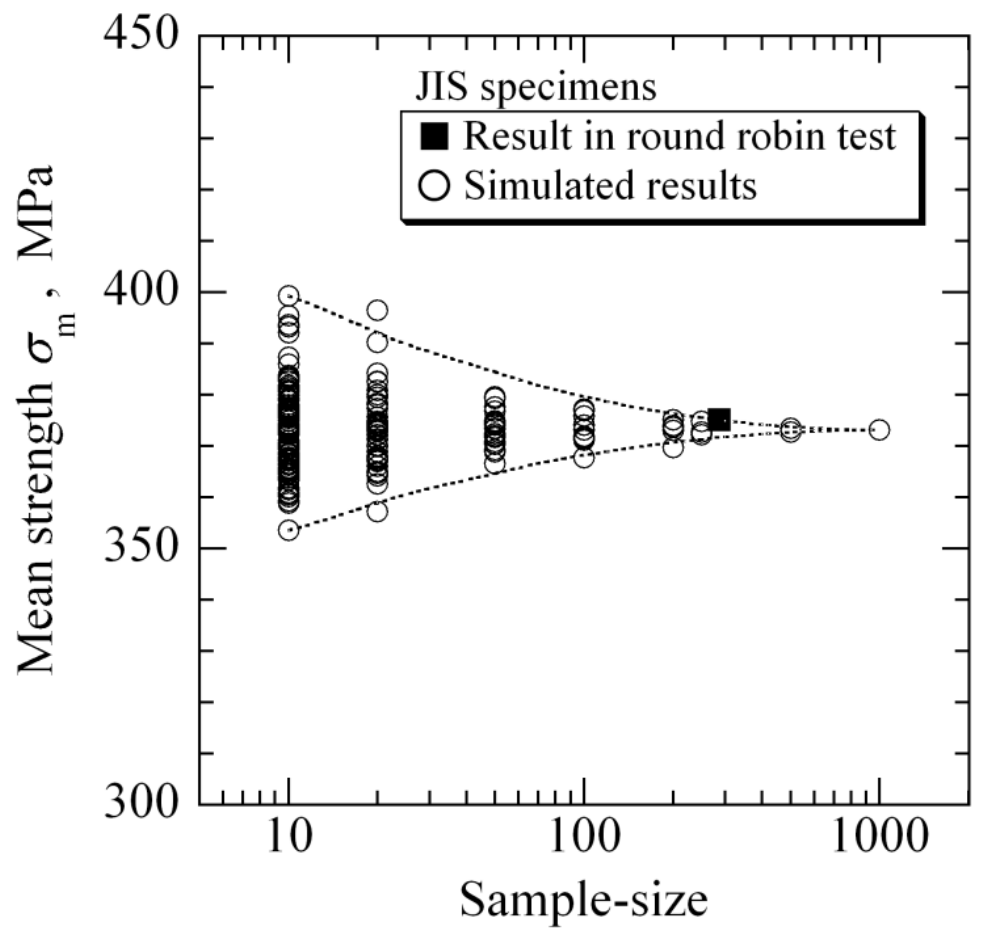

Fig. 4. Relations between mean strength and sample-size in JIS type specimen. 


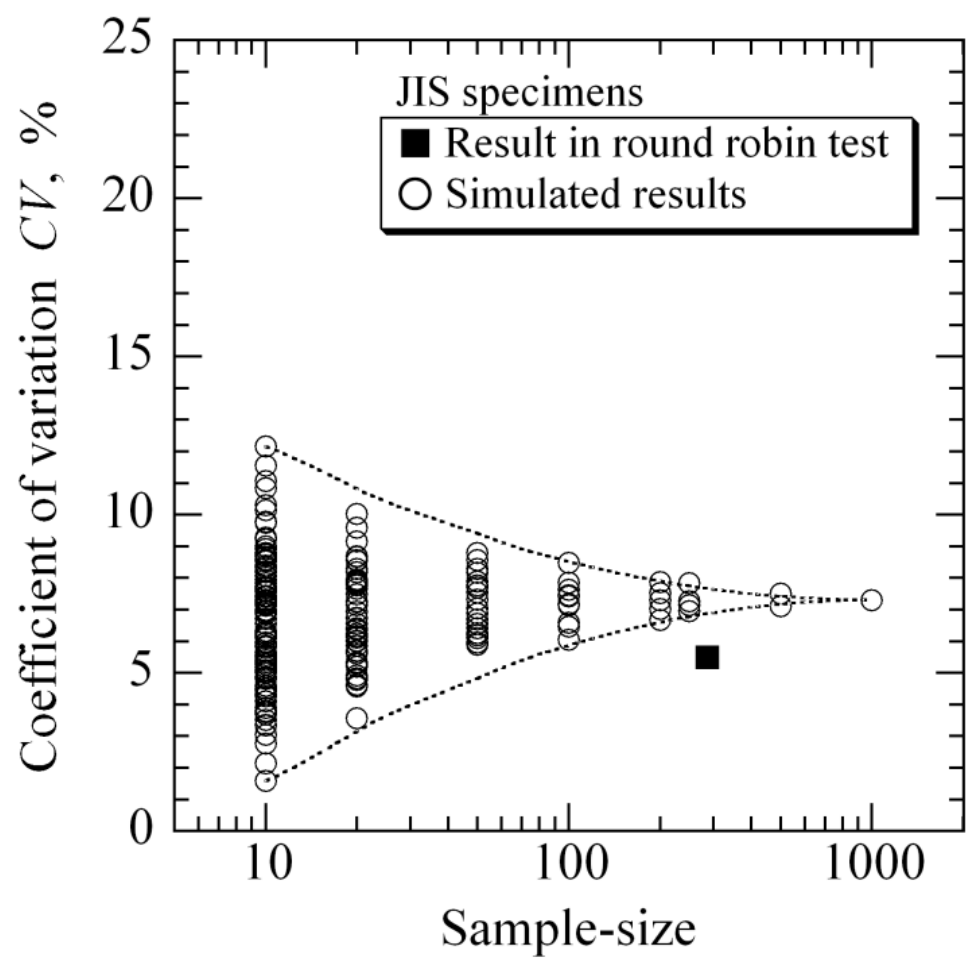

Fig. 5. Relations between coefficient of variation and sample-size in JIS type specimen.

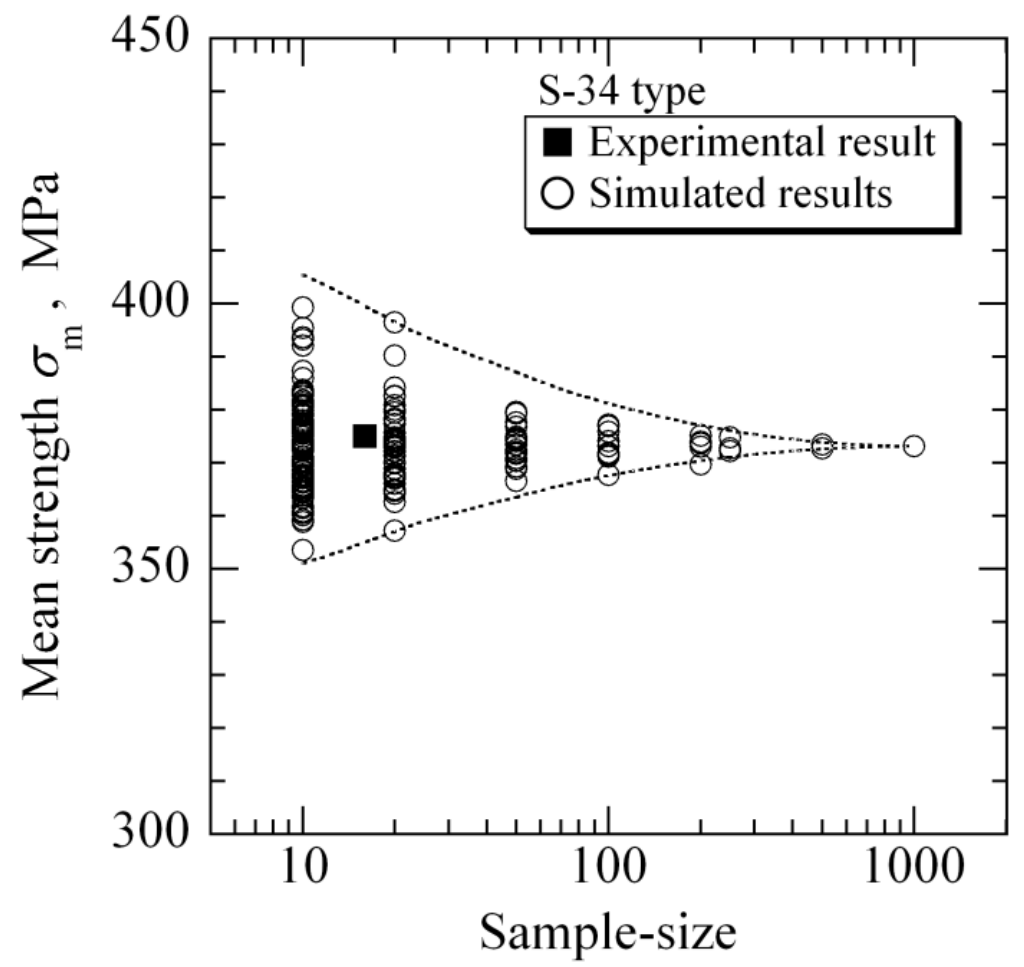

Fig. 6. Relations between mean strength and sample-size in S-34 type specimen 


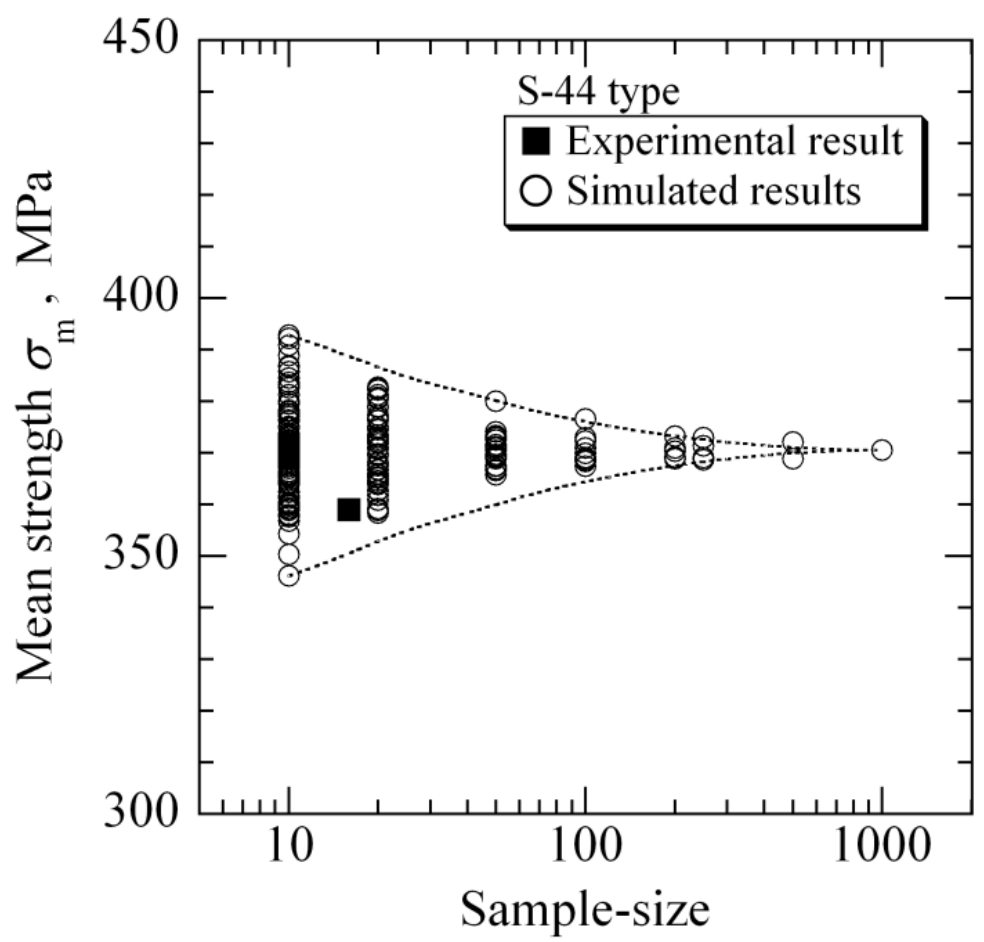

Fig. 7. Relations between mean strength and sample-size in S-44 type specimen.

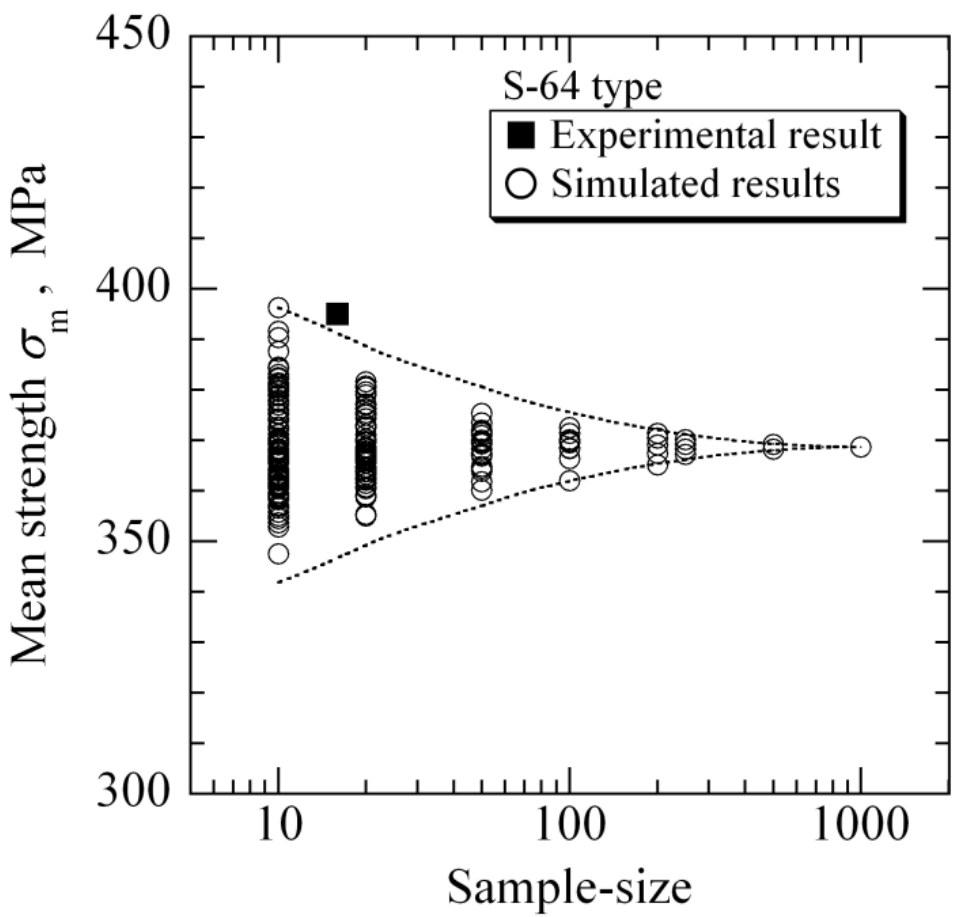

Fig. 8. Relations between mean strength and sample-size in S-64 type specimen. 


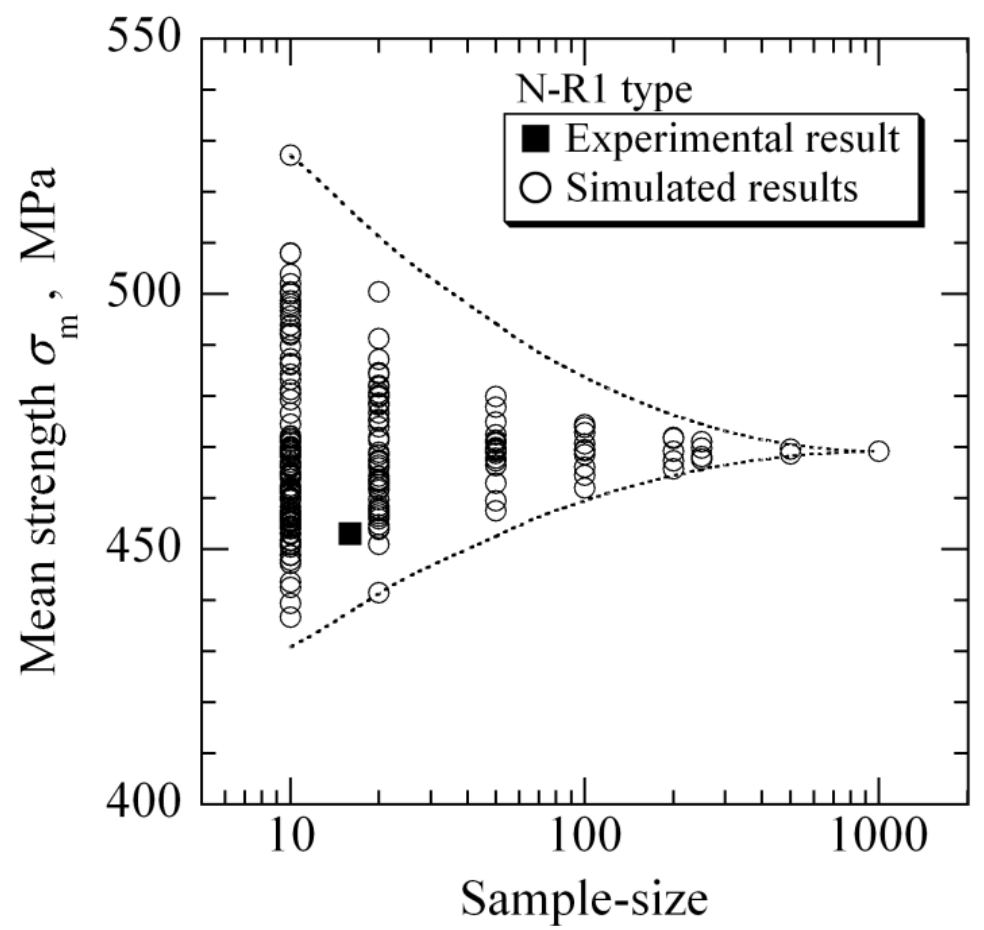

Fig. 9. Relations between mean strength and sample-size in N-R1 type specimen.



Fig. 10. Relations between mean strength and sample-size in N-R3 type specimen. 


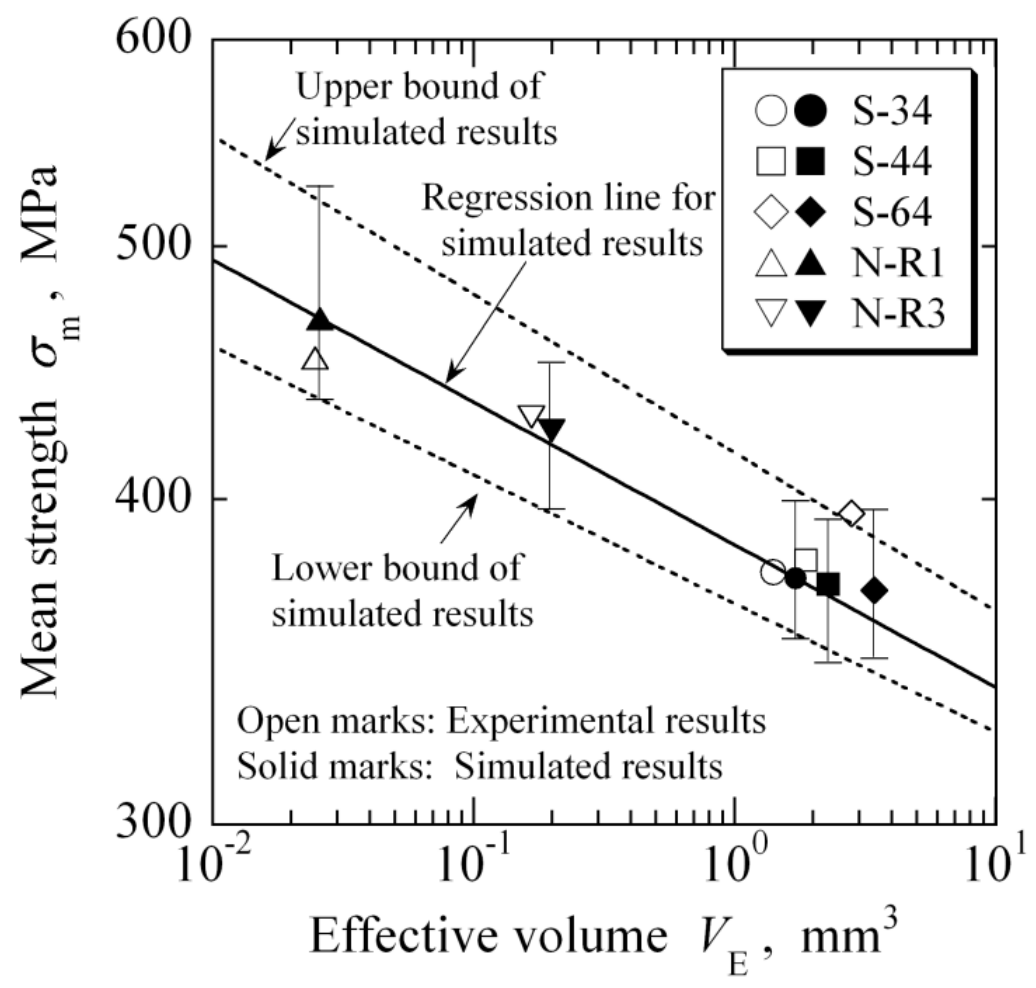

Fig. 11. Mean strength correlated with effective volume. 